\title{
R. Lorini • G. d'Annunzio \\ Comment to: Zalutskaya A, Bornstein SR, Mokhort T, Garmaev D (2004) Did the Chernobyl incident cause an increase in type 1 diabetes mellitus incidence in children and adolescents? Diabetologia 47:147-148 (Letter)
}

Received: 27 January 2005 / Accepted: 11 July 2005 / Published online: 26 August 2005

(C) Springer-Verlag 2005

\begin{abstract}
Abbreviations BMT: bone marrow transplantation - TBI: total-body irradiation
\end{abstract}

To the Editor: In the previous issue of Diabetologia, Zalutskaya et al. [1] evaluated the relation-ship between radiation contamination from the Chernobyl incident and the incidence of type 1 diabetes in two different regions of Belarus, i.e. the regions surrounding Gomel (highly exposed to radiation) and Minsk (minimally ex-posed), respectively. They found an increased incidence of the disease in the Gomel region as compared with the Minsk region. This finding is in contrast with the results of Bandurska-Stankiewicz et al. [2], who reported that in the region of Warmia and Mazury in the north of Poland, which was similarly exposed to the nuclear material released by the reactor explosion from Chernobyl, the incidence of type 1 diabetes did not increase after the event.

In our previous study of 34 patients (20 males and 14 females, aged 5.4-18.2 years) with acute or chronic leukaemia or non-malignant diseases, who underwent total body irradiation (TBI) or thoraco-abdominal irradiation (TAI) before autologous or allogenic bone marrow transplantation (BMT) [3], we evaluated beta cell function by IVGTT with measurement of first-phase insulin response and the insulinaemia : glycaemia ratio. None of the patients had autoantibodies against beta cells (islet cell autoantibodies and insulin autoantibodies). All patients had normal fasting blood glucose and $\mathrm{HbA}_{1} \mathrm{c}$ levels, whereas insulin

R. Lorini $(\bowtie) \cdot$ G. d'Annunzio

Department of Paediatrics, University of Genoa,

IRCCS G. Gaslini Institute,

Largo G. Gaslini 5,

16147 Genoa, Italy

e-mail: renatalorini@ospedale-gaslini.ge.it

Tel.: +39-010-5636654

Fax: +39-010-3773210 levels, the insulinaemia : glycaemia ratio and the firstphase insulin response were significantly higher in patients than in control subjects, particularly in those who underwent TBI. Our data suggest that children given TBI may develop a state of insulin resistance, as more recently reported by Taskinen et al. [4], who found a high risk of insulin resistance in patients who underwent TBI before BMT in childhood. Moreover, in personnel who took part in the cleaning-up operation after the Chernobyl nuclear incident, hyperinsulinaemia was observed and was interpreted to be a direct or indirect consequence of irradiation [5]. Conversely, histochemical studies on the effect of lethal total body X-ray irradiation on the pancreas of dogs saved by autologous BMT showed that, while the exocrine pancreas was markedly reduced, the endocrine component was better preserved, especially insulin and pancreatic polypeptide secretory cells [6]. We therefore suggest that all subjects, particularly children, exposed to irradiation should be regularly investigated for early markers of risk of diabetes. In Japan, mass screening for diabetes in adult survivors of the Hiroshima atomic bomb between 1971 and 1992 revealed a 2.1 -fold increase in prevalence in males and a 2.0 -fold increase in females [7].

\section{References}

1. Zalutskaya A, Bornstein SR, Mokhort T, Garmaev D (2004) Did the Chernobyl incident cause an increase in Type 1 diabetes mellitus incidence in children and adolescents? Diabetologia 47:147-148 (Letter)

2. Bandurska-Stankiewicz E, Rutkowska J (2004) Comment to: Zalutskaya A, Bornstein SR, Mokhort T, Garmaev D (2003) Did the Chernobyl incident cause an increase in type 1 diabetes mellitus incidence in children and adolescents? Diabetologia 47:2049-2050 (Letter)

3. Lorini R, Cortona L, Scaramuzza A et al (1995) Hyperinsulinemia in children and adolescents after bone marrow transplantation. Bone Marrow Transplant 15:873-877 
4. Taskinen M, Saarinen-Pihkala UM, Hovi L, Lipsanen-Nyman M (2000) Impaired glucose tolerance and dyslipidaemia as late effects after bone marrow transplantation in childhood. Lancet 356:993-997

5. Kovalenko AN, Zueva NA, Gerasimenko TI, Efimov AS (2001) Hyperinsulinemia as a factor preceding body mass increase in liquidators of the Chernobyl nuclear accident [Article in Russian]. Lik Sprava 5-6:10-12
6. Michel C, Calvo W, Raghavachar A, Fliedner TM (1986) Histochemical studies on the effects of lethal total body Xirradiation on the pancreas of dogs rescued by autologous bone marrow transplantation. Cell Mol Biol 32:519-526

7. Ito C (1994) Trends in the prevalence of diabetes mellitus among Hiroshima atomic bomb survivors. Diabetes Res Clin Pract 24:S29-S35 